\title{
Clostridium difficile outbreak in Costa Rica: control actions and associated factors
}

\author{
Roy A. Wong-McClure, ${ }^{1}$ Moraima Guevara-Rodríguez, ${ }^{2}$ \\ Leandra Abarca-Gómez, ${ }^{1}$ Antonio Solano-Chinchilla, ${ }^{2}$ \\ Margarita Marchena-Picado, ${ }^{2}$ Michele O'Shea, ${ }^{3}$ \\ and Xiomara Badilla-Vargas ${ }^{1}$
}

Suggested citation

Wong-McClure RA, Guevara-Rodríguez M, Abarca-Gómez L, Solano-Chinchilla A, Marchena-Picado M, O'Shea M, Badilla-Vargas X. Clostridium difficile outbreak in Costa Rica: control actions and associated factors. Rev Panam Salud Publica. 2012;32(6):413-8.

ABSTRACT Objective. To describe interventions implemented during a nosocomial outbreak of Clostridium difficile in a general hospital in Costa Rica from December 2009 to April 2010 in order to achieve outbreak control and the factors determined to be associated with $\mathrm{C}$. difficile infection. Methods. Laboratory-confirmed cases of $\mathrm{C}$. difficile were analyzed to describe the outbreak pattern and intervention measures implemented. Cases were selected and recruited in a casecontrol study. Controls were selected from the same services and time period as the cases. Evaluated exposures included underlying medical conditions and treatments administered before the onset of symptoms.

Results. The mean ages in case and control groups were 62.3 and 55.3 years, respectively. Control measures included a hand-hygiene campaign, deep disinfection of hospital surfaces, strict isolation of cases, use of personal protection equipment, and restriction of antibiotic use. The adjusted attributable risks associated with the outbreak were diabetes [odds ratio (OR) 3.4, 95\% confidence interval (CI) 1.5-7.7], chronic renal failure (OR 9.0,95\% CI 1.5-53.0), and prescribing ceftazidime (OR 33.3, 95\% CI 2.9-385.5) and cefotaxime (OR 20.4, 95\% CI 6.9-60.3). Conclusions. Timely implementation of control measures resulted in reduced infection transmission and successful control of the outbreak. Conditions associated with $\mathrm{C}$. difficile infection were similar to those found in previously described outbreaks of this bacterium.

Key words Clostridium difficile; enterocolitis; Costa Rica.

Clostridium difficile-associated diarrhea (CDAD), caused by the ingestion of C. difficile spores, has been recognized as an increasingly common nosocomial in-

\footnotetext{
1 Salud Colectiva, Subárea de Epidemiología, Caja Costarricense de Seguro Social, San José, Costa Rica. Send correspondence to: Roy A. Wong-McClure, rwong@ccss.sa.cr

2 Hospital Calderón Guardia, Caja Costarricense de Seguro Social, San José, Costa Rica.

3 University of Arizona College of Medicine, Phoenix, Arizona, United States of America.
}

fection (1). It is defined as the presence of diarrheal disease and a positive toxin assay (2). Several C. difficile outbreaks have been described in the literature and have been associated with various factors, including decreased immunocompetence and administration of drugs, particularly fluoroquinolones, cephalosporins, and proton-pump inhibitors (3-6).

Such outbreaks have been scarcely documented in Latin American coun- tries, with the exception of the outbreaks described in Brazilian intensive care units. A previous $C$. difficile outbreak of the BI/NAP1 strain was documented in Costa Rica in 2009. The organism was identified in more than half of the isolated strains (7). However, such prior reports have been limited in their description of the infectious agent and their characterization of the infection control strategies implemented in intensive care 
units, and they have not extensively explored factors associated with the outbreak in critical care patients, especially with regard to underlying conditions (8).

In 2010, a non-BI strain $C$. difficile outbreak was identified in a general hospital in Costa Rica, which affected the medical and surgical wards. The aim of this investigation was to describe the infection control strategies implemented in this case and to determine the factors associated with the outbreak.

\section{MATERIALS AND METHODS}

The affected facility was a Costa Rican tertiary care hospital with 563 beds and an average of 24000 discharges annually. The hospital provides medical, surgical, and gynecologic services to a population of approximately 850000 .

A C. difficile outbreak was reported in this hospital in December 2009, with an initial increase in the monthly incidence rate of CDAD from a baseline of 0.3 to 0.6 case per 10000 patient-days to 2.4 cases per 10000 patient-days during the outbreak.

A descriptive analysis of C. difficile was conducted to characterize disease patterns between January 2009 and June 2011. An unmatched case-control study was performed from December 2009 to April 2010.

\section{Selection of subjects}

Selected patients were the CDAD cases reported during the outbreak period. The working definition of CDAD was all patients with diarrheal disease (more than two episodes of watery stools in 24 hours) 72 hours after hospital admission who did not have diarrheal symptoms upon admission, confirmed with a positive $C$. difficile test. It was necessary to exclude patients with diarrhea before the first 72 hours of hospitalization or those with diarrhea as the cause of admission in order to eliminate possible community $C$. difficile cases in accordance with the Society for Healthcare Epidemiology of America and the Infectious Diseases Society of America (9).

\section{Selection of control subjects}

Control subjects were randomly selected among patients hospitalized during the same time period as the case subjects. The neonatology, gynecology, obstetrics, and outpatient surgery wards, which did not report cases, were excluded from the selection process. To avoid including false-negative $C$. difficile cases, exclusion criteria were patients with diarrheal disease as the reason for admission. Patients who developed diarrheal disease during the hospital stay due to etiologic agents or conditions other than $C$. difficile were also excluded. The $C$. difficile toxin detection test used had a sensitivity of $95.2 \%$; to improve it, patients with diarrhea not related to $C$. difficile were excluded.

The control sample frame was the patient hospitalization information system and random selection was done by sample random command from Stata 10.1 (Stata Corporation, College Station, Texas, United States of America, 2009).

As a result, data collection was substantially cheaper and easier for the controls than for the case samples; therefore, the selected number of controls per case was six, which is higher than the standard recommended four controls per case for reasonable study efficiency (10).

\section{Evaluation of exposures}

Exposures were obtained based on several information sources. General patient features, medical history, and hospitalization data were collected from the hospital information system. Drug prescription data were obtained from the hospital drug information system, while the associated symptom and mortality data were collected from the nosocomial infection surveillance system.

The nosocomial infection surveillance system collects data for routine surveillance of all wards and is collected by nurses, who record information related to nosocomial infections, procedures, and medical conditions of affected patients. All data sets were integrated to a master data set.

Length of hospitalization was determined as the entire hospitalization period for control subjects and from the first day of hospitalization to the date of onset of symptoms for case subjects.

The window of exposure was defined as a period of three weeks preceding the date of onset of symptoms for case subjects and three weeks before the date of discharge for control subjects. The window period was defined based on the unknown incubation period of $C$. difficile and the 12-day average hospitalization stay in the affected hospital.

\section{Laboratory analysis}

C. difficile toxin was determined by testing fresh stool 1 hour after sample collection. An Immuno Card toxin A\&B (Meridian Bioscience, Inc., Cincinnati, Ohio, United States of America) was used as the C. difficile toxin detection test.

Toxin-positive isolates were confirmed by culture and the isolates were recovered by placing inoculating loops of stool samples onto cefoxitin cycloserine fructose agar plates (Oxoid Ltd., Basingstoke, United Kingdom). The isolates were identified by the rapid ID32A system (bioMérieux, Inc., Durham, North Carolina, United States of America) and polymerase chain reaction amplification of the triosephosphate isomerase gene. The isolates were typed by pulsed-field gel electrophoresis and fragments of $t c d A, t c d B, t c d C$, and $c d t B$ genes were amplified by polymerase chain reaction with oligonucleotides. All isolates were positive for the $t c d A$ and $t c d B$ and non-BI strain.

\section{Data analysis}

A descriptive analysis of general variables by group was initially conducted. The comparison of general features between cases and controls was done with the chi-square test for categorical variables and the $t$-test for comparison of means.

The odds ratio (OR) was calculated to estimate the likelihood of association between the evaluated exposures and the development of CDAD. The conditions associated with CDAD were then assessed with a bivariate model. An adjusted OR was estimated with a logistic regression model for variables that demonstrated association or that were identified as confounders. Backward stepwise regression was then performed and variables with a $P$ value $>0.20$ were excluded

All estimations were calculated with Stata 10.1 at a significance level of 0.05. Ethical approval was not necessary for this investigation, in accordance with the country's bioethical regulations at the time of the start of the outbreak investigation, and the patients' confidentiality was maintained during the study, with a unique code assignment by the hospital control infection committee. The final version of the manuscript was evaluated and approved to be submitted for publication by the Caja Costarricense de Seguro Social (CCSS) bioethical office. 
FIGURE 1. Clostridium difficile incidence rate by month and year, Costa Rican General Hospital, 2009 to June 2011

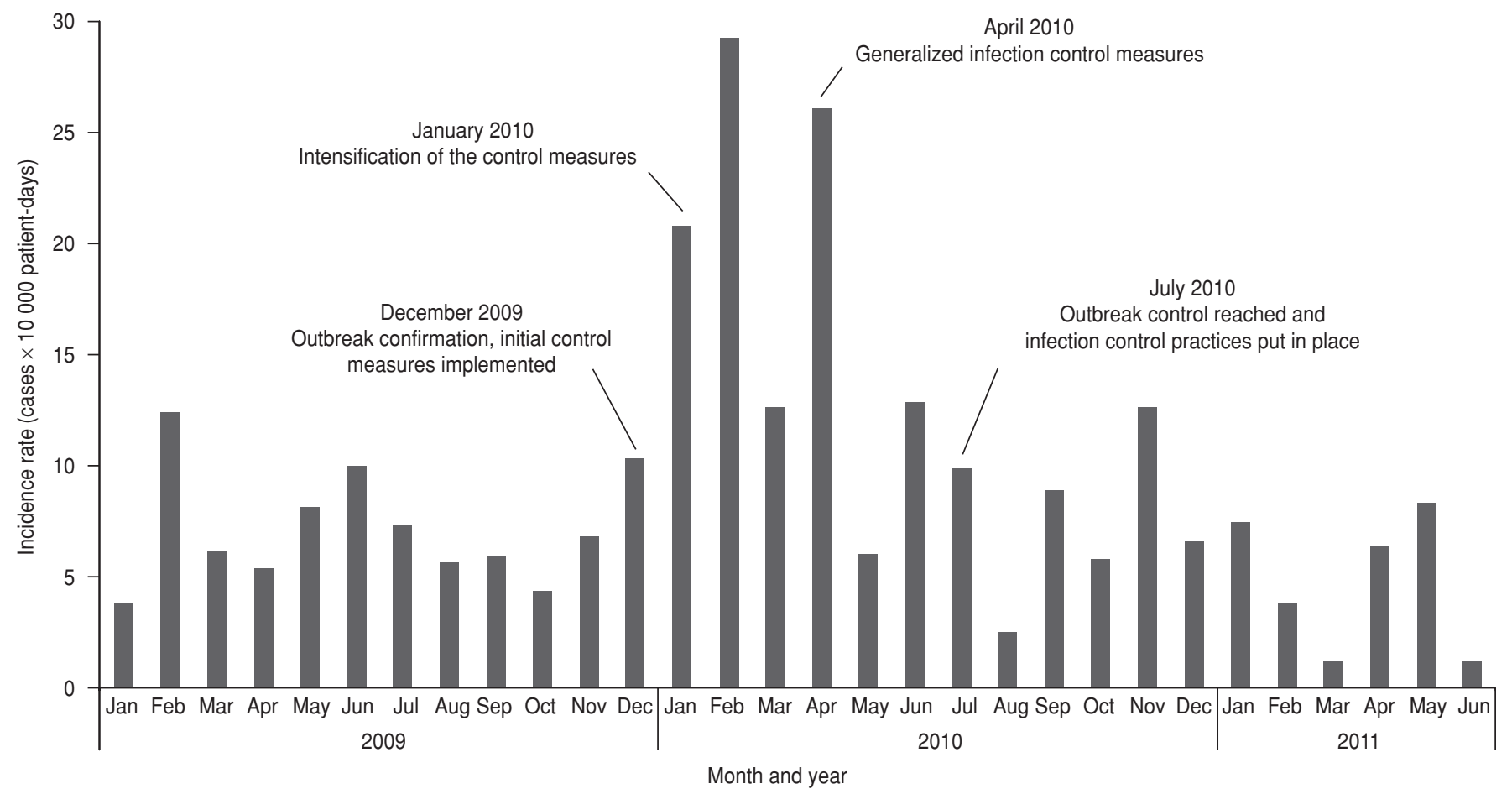

The data from this investigation are the property of CCSS, the public health care provider of the Costa Rican government.

\section{RESULTS}

\section{General overview of the outbreak}

During the outbreak period, a total of 84 cases were identified on the medical and surgical wards. The usual incidence rate of 3.1 to 6.7 cases per 10000 patientdays increased 5-fold, with 24.3 cases per 10000 patient-days in February 2010.

The outbreak was confirmed in the last week of December 2009, and initial control measures based on the CCSS C. difficile outbreak guidelines were implemented solely in wards with positive cases (11). Initial strategies included a hand-hygiene enforcement campaign for medical staff and patients, mandatory use of personal protective equipment by facility employees in contact with patients suspected of being infected, strict isolation measures, a deep disinfection protocol, and restriction of the use of antibiotics associated with CDAD. A strict isolation area was set up for patients with confirmed cases of $C$. difficile. Deep disinfection was performed on surfaces in patients' rooms and on equipment used through a procedure of double

TABLE 1. General features of Clostridium difficile-associated diarrhea cases and controls, Costa Rican general hospital, 2010

\begin{tabular}{|c|c|c|c|c|}
\hline \multirow[b]{2}{*}{ Variable } & \multicolumn{2}{|c|}{ Controls $(n=552)$} & \multicolumn{2}{|c|}{ Cases $(n=84)$} \\
\hline & No. & $\%$ & No. & $\%$ \\
\hline \multicolumn{5}{|l|}{ Sex } \\
\hline Male & 270 & 48.9 & 36 & 42.9 \\
\hline Female & 282 & 51.1 & 48 & 57.1 \\
\hline \multicolumn{5}{|l|}{ Medical history } \\
\hline Diabetes & 78 & 14.1 & 32 & 38.1 \\
\hline Cancer & 0 & 0.0 & 14 & 16.7 \\
\hline Ulcerative colitis & 0 & 0.0 & 0 & 0.0 \\
\hline Chronic renal failure & 5 & 0.9 & 4 & 4.8 \\
\hline Immunosuppression & 0 & 0.0 & 8 & 9.5 \\
\hline
\end{tabular}

cleaning, with 45 minutes between each cleaning. The solutions used were a 1:10 hypochlorite solution in the medical wards and 1:10 quaternary ammonium for medical equipment.

The restricted antibiotics were those previously recommended in the literature, which include fluoroquinolones, clindamycin, and third-generation cephalosporins and carbapenems.

The initial control measures had been implemented in affected areas of the hospital in December 2009 and were intensified in January 2010. Four weeks later, the initial trend of the epidemiologic curve was interrupted. However, in April 2010 another increase in the incidence rate from the same wards was ob- served, but it was found in patients who had been referred from other wards. At this point, the described measures were applied to all areas of the hospital. After expanded implementation of these control measures, the outbreak was declared controlled in July 2010.

The control measures were maintained until the first semester of 2011 as part of routine prevention of further $C$. difficile nosocomial outbreaks and proved effective in reestablishing the usual incidence pattern of CDAD (Figure 1).

\section{Associated factors}

General patient features are described in Table 1. Females experienced a greater 
frequency of CDAD in both the case and the control groups. The average age was 55.3 years [standard deviation (SD) 18.8 years] for the control group and 62.3 years (SD 21.8 years) for the case group. The difference in the average age between the two groups was significant $(P=0.02)$.

Underlying medical conditions such as diabetes, cancer, chronic renal failure, and immunosuppression were more frequent in case subjects than in control subjects (Table 1).

The most frequent clinical presentation associated with diarrheal disease was abdominal pain, which was present in $23.8 \%$ of patients, in addition to fever and leukocytosis, which together were present in $21.4 \%$ of patients.

The average length of hospitalization was 11.5 days (SD 14.0 days) for cases and 7.8 days (SD 7.7 days) for controls. The most frequently prescribed antibiotics were cefotaxime, clindamycin, and oxacillin for patients in the case group; clindamycin, gentamicin, and ciprofloxacin were prescribed more often in the control group.

According to the nonadjusted ORs of each group, subjects older than 59 years with a hospitalization stay longer than 7 days, diabetes, and chronic renal failure were the conditions most significantly associated with risk of CDAD. The evaluation of drug exposures revealed an association with antibiotics, in particular ceftazidime, cefotaxime, meropenem, and levofloxacin.

The adjusted OR demonstrated that CDAD was associated with underlying medical conditions of diabetes [OR 3.4, 95\% confidence interval (CI) 1.5-7.7, $P=0.04]$ and chronic renal failure (OR 9.0, 95\% CI 1.5-53.0, $P=0.02$ ). Other conditions that maintained association in the adjusted model were administration of cephalosporins, including ceftazidime (OR 33.3, 95\% CI 2.9-385.5, $P<0.01$ ) and cefotaxime (OR 20.4, 95\% CI 6.9-60.3, $P<0.01)$, before the onset of symptoms (Table 2).

\section{DISCUSSION}

The results demonstrate that the incidence rate observed in C. difficile outbreaks can rise dramatically within a matter of weeks, a phenomenon that can be explained by a mechanism of bacterial transmission in which hospital surfaces are contaminated with spores. The incidence rate of 2.4 cases per 10000

Table 2. Factors associated with Clostridium difficile infection, Costa Rican general hospital, 2010

\begin{tabular}{|c|c|c|c|c|c|c|c|c|}
\hline Variable & $\begin{array}{l}\text { Controls } \\
(n=552)\end{array}$ & $\begin{array}{l}\text { Cases } \\
(n=84)\end{array}$ & OR & $95 \% \mathrm{Cl}$ & $P$ & $\begin{array}{l}\text { Adjusted } \\
\text { OR }\end{array}$ & $95 \% \mathrm{Cl}$ & $P$ \\
\hline \multicolumn{9}{|l|}{ Sex } \\
\hline Male & 270 & 36 & 1.0 & & & & & \\
\hline Female & 282 & 48 & 1.3 & $0.7-2.1$ & 0.30 & 1.3 & $0.6-2.9$ & 0.47 \\
\hline \multicolumn{9}{|l|}{ Age, years } \\
\hline$<60$ & 440 & 53 & 1.0 & & & & & \\
\hline$\geq 60$ & 112 & 31 & 2.3 & $1.3-3.8$ & $<0.001$ & 1.4 & $0.6-3.2$ & 0.37 \\
\hline \multicolumn{9}{|l|}{ Location } \\
\hline Medical ward & 178 & 45 & 2.4 & $1.4-3.9$ & $<0.001$ & 0.9 & $0.4-2.0$ & 0.87 \\
\hline Surgical ward & 374 & 39 & 1.0 & & & & & \\
\hline \multicolumn{9}{|l|}{$\begin{array}{l}\text { Length of } \\
\text { hospitalization, days }\end{array}$} \\
\hline$\leq 7$ & 437 & 55 & 1.0 & & & & & \\
\hline$>7$ & 115 & 29 & 2.0 & $1.1-3.4$ & $<0.001$ & 1.0 & $1.0-1.1$ & 0.07 \\
\hline \multicolumn{9}{|l|}{ Medical history } \\
\hline Diabetes & 78 & 32 & 3.7 & $1.8-7.6$ & $<0.001$ & 3.4 & $1.5-7.7$ & 0.04 \\
\hline Cancer & 0 & 14 & NC & & & & & \\
\hline Ulcerative colitis & 0 & 0 & $\mathrm{NC}$ & & & & & \\
\hline Chronic renal failure & 5 & 4 & 5.5 & $0.5-34.5$ & 0.02 & 9.0 & $1.5-53.0$ & 0.02 \\
\hline Immunosuppression & 0 & 8 & NC & & & & & \\
\hline \multicolumn{9}{|l|}{ Cephalosporins } \\
\hline Cefotaxime & 28 & 8 & 34.0 & $11.9-100.1$ & $<0.001$ & 20.4 & $6.9-60.3$ & $<0.01$ \\
\hline Cefalotin & 10 & 38 & 1.8 & $0.5-1.0$ & $0.21^{a}$ & & & \\
\hline Cefalexin & 2 & 49 & 0.2 & $0.0-1.5$ & $0.24^{a}$ & & & \\
\hline Ceftazidime & 10 & 1 & 74.4 & $7.7-3526.5$ & $<0.001^{\mathrm{a}}$ & 33.3 & $2.9-85.5$ & $<0.01$ \\
\hline \multicolumn{9}{|l|}{ Penicillins } \\
\hline Amoxicillin & 0 & 25 & NC & & & & & \\
\hline Penicillin & 0 & 2 & NC & & & & & \\
\hline Oxacillin & 14 & 85 & 1.1 & $0.4-2.6$ & 0.82 & & & \\
\hline \multicolumn{9}{|l|}{ Quinolones } \\
\hline Ciprofloxacin & 12 & 90 & 0.8 & $0.3-2.1$ & 0.73 & & & \\
\hline Levofloxacin & 12 & 19 & 4.7 & $1.4-13.1$ & $<0.001$ & 0.9 & $0.2-4.1$ & 0.94 \\
\hline \multicolumn{9}{|l|}{ Macrolides } \\
\hline Clarithromycin & 8 & 43 & 1.2 & $0.3-3.7$ & $0.56^{a}$ & & & \\
\hline \multicolumn{9}{|l|}{ Aminoglycosides } \\
\hline Gentamicin & 10 & 120 & 0.5 & $0.1-1.3$ & 0.16 & & & \\
\hline Amikacin & 6 & 25 & 1.6 & $0.3-5.7$ & 0.44 & & & \\
\hline \multicolumn{9}{|l|}{ Carbapenems } \\
\hline Meropenem & 8 & 8 & 7.2 & $1.5-27.9$ & $<0.01$ & 2.4 & $0.4-14.7$ & 0.35 \\
\hline \multicolumn{9}{|l|}{ Tetracyclines } \\
\hline Doxycycline & 2 & 17 & 0.8 & $0.0-5.2$ & 1.0 & & & \\
\hline \multicolumn{9}{|l|}{ Sulfonamide } \\
\hline $\begin{array}{l}\text { Trimethoprim- } \\
\text { sulfamethoxazole }\end{array}$ & 6 & 72 & 0.5 & $0.1-1.7$ & 0.27 & & & \\
\hline \multicolumn{9}{|l|}{ Lincosamide } \\
\hline Clindamycin & 16 & 120 & 0.8 & $0.3-1.9$ & 0.68 & & & \\
\hline \multicolumn{9}{|l|}{$\begin{array}{l}\text { 5-Aminosalicylic acid } \\
\text { derivative }\end{array}$} \\
\hline Sulfasalazine & 0 & 2 & $\mathrm{NC}$ & & & & & \\
\hline \multicolumn{9}{|l|}{ Gastric acid } \\
\hline Esomeprazole & 2 & 1 & 13.4 & $0.2-1056.6$ & $0.14^{a}$ & 2.0 & $0.5-77.7$ & 0.71 \\
\hline
\end{tabular}

Notes: OR: odds ratio, $\mathrm{Cl}$ : confidence interval, NC: not calculable.

a Fisher's exact test.

patient-days in this Costa Rican hospital was lower than what has been reported in previous studies in the United States of America and Canada (12), a condition that could be related to factors such as the $C$. difficile reported strain, the different hospital sizes, and the complex level. Nonetheless, the high transmissibility of C. difficile infection emphasizes the importance of rapid implementation of the comprehensive infection control measures to prevent further cases.
The current outbreak was controlled by implementation of guidelines established by the CCSS in 2009, which included strategies that have proven to be successful in achieving outbreak control in other documented cases (13-15), although the efficacy of each individual intervention in this case is not known. The prescription of high-risk antibiotics as the most important factor associated with CDAD supports enforcement of the restriction of antimicrobial use as part of recommended 
control measures, which was appropriately implemented in this case to achieve outbreak control. Several described C. difficile outbreaks have considered antibiotic restriction as an effective control strategy, especially with regard to fluoroquinolones and cephalosporins $(14,16)$. The use of fluoroquinolones has been reported to be one of the most important factors associated with CDAD (14). The study did not find an association with fluoroquinolones, which could be explained by the concomitant prescription of this medication with other antibiotics associated with CDAD that resulted in larger differences between case and control exposures than the exposures between those groups and fluoroquinolones.

Increased age has been associated with increased susceptibility to CDAD (17), a condition that was shown to be relevant during the outbreak with a significantly higher mean age in the case group than in the control group.

The underlying medical conditions associated with CDAD in this outbreak have been described as risk factors mainly in patients who had undergone surgery (18, 19). However, association of these underlying medical conditions with CDAD during this outbreak was independent of a history of surgical procedures. The described association thus could more likely have resulted from increased susceptibility due to antibiotic use than from the surgical procedures.
The main limitation of the study was the diagnostic test used to determine infection status. This assay is based on the presence of $C$. difficile toxin, which is not the most sensitive method of establishing the presence of this toxigenic bacterium. To limit the possibility of false negatives in the control group, all patients with previous diarrheal disease were excluded. During the time of the outbreak, this test was the only one being used to determine CDAD in the affected hospital.

This study evaluated the infection control measures implemented during a hospital outbreak and established various factors associated with a $C$. difficile outbreak in a Latin American country. Few studies of such outbreaks have been published in this region, where the availability of resources and health conditions experienced are very different from those in other parts of the world.

In this case, the initial incidence rate of the outbreak experienced a significant reduction during the weeks after implementation of infection control measures, which were shown to effectively achieve outbreak control. This result is consistent with reports of similar outbreaks in which such interventions were enforced in conjunction with early detection of infection $(2,20)$.

A large body of evidence related to $C$. difficile as a nosocomial agent has been documented and the investigation of this
Costa Rican C. difficile outbreak has confirmed that the findings are consistent with previously described risk factors for development of CDAD (18). This study also confirms the importance of rapid implementation of such interventions (20) to reduce transmission of the disease and the impact of the outbreak.

As part of the development of effective strategies for preventing and controlling C. difficile outbreaks, it is important that the design of such protocols in each hospital follow evidence-based guidelines $(9,20)$. These guidelines include environmental strategies, hand-hygiene enforcement campaigns, disinfection of surfaces, and restrictive use of high-risk antibiotics.

The nosocomial surveillance system must improve the sensitivity of $C$. difficile testing methods to ensure timely detection of future outbreaks and implementation of control measures to prevent the incidence of further cases and transmission to other hospital wards.

Acknowledgments. Special gratitude goes to the personnel of Infection Control, Clinical Laboratory, Medical Records and Pharmacy Service of the affected hospital, who contributed to data collection during the outbreak period. Financial support was provided by CCSS, the Costa Rican health supplier governmental agency.

\section{REFERENCES}

1. Paredes-Sabja D, Bond C, Carman RJ, Setlow $\mathrm{P}$, Sarker MR. Germination of spores of Clostridium difficile strains, including isolates from a hospital outbreak of Clostridium difficileassociated disease (CDAD). Microbiology. 2008;154(Pt 8):2241-50.

2. Kutty PK, Benoit SR, Woods CW, Sena AC, Naggie S, Frederick J, et al. Assessment of Clostridium difficile-associated disease surveillance definitions, North Carolina, 2005. Infect Control Hosp Epidemiol. 2008;29(3):197-202.

3. Kazakova SV, Ware K, Baughman B, Bilukha $\mathrm{O}$, Paradis A, Sears S, et al. A hospital outbreak of diarrhea due to an emerging epidemic strain of Clostridium difficile. Arch Intern Med. 2006;166(22):2518-24.

4. Dalton BR, Lye-Maccannell T, Henderson EA, Maccannell DR, Louie TJ. Proton pump inhibitors increase significantly the risk of Clostridium difficile infection in a low-endemicity, non-outbreak hospital setting. Aliment Pharmacol Ther. 2009;29(6):626-34.

5. Salgado CD, Mauldin PD, Fogle PJ, Bosso JA. Analysis of an outbreak of Clostridium difficile infection controlled with enhanced infection control measures. Am J Infect Control. 2009;37(6):458-64.

6. Polgreen PM, Chen YY, Cavanaugh JE, Ward M, Coffman S, Hornick DB, et al. An outbreak of severe Clostridium difficile-associated disease possibly related to inappropriate antimicrobial therapy for community-acquired pneumonia. Infect Control Hosp Epidemiol. 2007;28(2):212-4.

7. Quesada-Gómez C, Rodríguez C, GamboaCoronado $\mathrm{M}$ del $\mathrm{M}$, Rodríguez-Cavallini $\mathrm{E}$, $\mathrm{Du}$ T, Mulvey MR, et al. Emergence of Clostridium difficile NAP1 in Latin America. J Clin Microbiol. 2010;48(2):669-70.

8. Borges SL, Pinheiro B do V, Pace FH de L, Chebli JMF. Diarréia nosocomial em unidade de terapia intensiva: incidência e fatores de risco. Arq Gastroenterol. 2008;45(2):117-23.

9. Cohen SH, Gerding DN, Johnson S, Kelly CP, Loo VG, McDonald LC, et al. Clinical practice guidelines for Clostridium difficile infection in adults: 2010 update by the society for healthcare epidemiology of America (SHEA) and the infectious diseases society of America (IDSA). Infect Control Hosp Epidemiol. 2010;31(5):431-55.

10. Ahrens W, Pigeot I, eds. Handbook of epidemiology. New York: Springer; 2005.

11. Caja Costarricense de Seguro Social. Lineamientos para la vigilancia de Clostridium difficile en la red hospitalaria de la Caja Costarricense de Seguro Social. San José: Caja Costarricense de Seguro Social; 2009.

12. Pépin J, Valiquette L, Cossette B. Mortality attributable to nosocomial Clostridium difficileassociated disease during an epidemic caused by a hypervirulent strain in Quebec. CMAJ. 2005;173(9):1037-42.

13. Weiss K, Boisvert A, Chagnon M, Duchesne C, Habash S, Lepage Y, et al. Multipronged intervention strategy to control an outbreak of Clostridium difficile infection (CDI) and its impact on the rates of CDI from 2002 to 2007. Infect Control Hosp Epidemiol. 2009;30(2): 156-62.

14. Kallen AJ, Thompson A, Ristaino P, Chapman L, Nicholson A, Sim B-T, et al. Complete 
restriction of fluoroquinolone use to control an outbreak of Clostridium difficile infection at a community hospital. Infect Control Hosp Epidemiol. 2009;30(3):264-72.

15. Barbut F, Jones G, Eckert C. Epidemiology and control of Clostridium difficile infections in healthcare settings: an update. Curr Opin Infect Dis. 2011;24(4):370-6.

16. Gould D. Prevention and control of Clostridium difficile infection. Nurs Older People. 2010;22(3):29-34; quiz 35.

17. Viswanathan V, Mallozzi M, Vedantam G. Clostridium difficile infection: an overview of the disease and its pathogenesis, epidemiology and interventions. Gut Microbes. 2010;1(4):234-42.

18. Voth DE, Ballard JD. Clostridium difficile toxins: mechanism of action and role in disease. Clin Microbiol Rev. 2005;18(2):247-63.

19. Zerey M, Paton BL, Lincourt AE, Gersin KS, Kercher KW, Heniford BT. The burden of Clostridium difficile in surgical patients in the United States. Surg Infect (Larchmt). 2007;8(6):557-66.

20. Vonberg RP, Kuijper EJ, Wilcox MH, Barbut F, Tüll P, Gastmeier P, et al. Infection control measures to limit the spread of Clostridium difficile. Clin Microbiol Infect. 2008;14(Suppl 5):2-20.

Manuscript received on 30 July 2011. Revised version accepted for publication on 9 September 2012.

RESUMEN Objetivo. Describir las intervenciones ejecutadas durante un brote intrahospitalario de infección por Clostridium difficile en un hospital general de Costa Rica desde diciembre del 2009 hasta abril del 2010 para lograr el control del brote y de los factores asociados a la infección por C. difficile.

Brote de infección por Clostridium difficile en Costa Rica: medidas de control y factores asociados
Métodos. Se analizaron los casos de infección por C. difficile que se habían confirmado mediante pruebas de laboratorio a fin de describir las características del brote y las medidas que se tomaron. Se seleccionaron los casos y se incluyeron en un estudio de casos y testigos; se seleccionaron los testigos en los mismos servicios y el mismo periodo que los casos. Las exposiciones evaluadas incluían las afecciones médicas subyacentes y los tratamientos administrados antes de que comenzaran los síntomas.

Resultados. La media de la edad en los grupos de los casos y de los testigos fue de 62,3 años y 55,3 años, respectivamente. Las medidas de control incluyeron una campaña de promoción de la higiene de las manos, la desinfección a fondo de las superficies hospitalarias, el aislamiento estricto de los casos, el uso de equipo de protección personal y la restricción del uso de antibióticos. Los riesgos atribuibles ajustados que se asociaron al brote fueron la diabetes (razón de posibilidades [OR]: 3,4; intervalo de confianza [IC] de 95\%: 1,5-7,7), la insuficiencia renal crónica (OR: 9,0; IC de 95\%: 1,5-53,0) y el uso de ceftazidima (OR: 33,3; IC de 95\%: 2,9-385,5) y cefotaxima (OR: 20,4; IC de 95\%: 6,9-60,3).

Conclusiones. La aplicación oportuna de medidas de control redujo la transmisión de la infección y permitió controlar satisfactoriamente el brote. Las afecciones y los factores que se asociaron a la infección por $C$. difficile fueron similares a los que se encontraron en brotes de esta infección descritos anteriormente. 